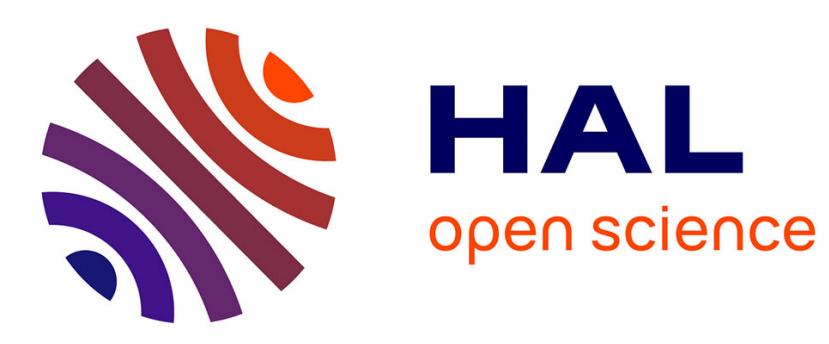

\title{
Vesicle Tubulation with Self-Assembling DNA Nanosprings
}

Michael W Grome, Zhao Zhang, Frédéric Pincet, Chenxiang Lin

\section{To cite this version:}

Michael W Grome, Zhao Zhang, Frédéric Pincet, Chenxiang Lin. Vesicle Tubulation with SelfAssembling DNA Nanosprings. Angewandte Chemie International Edition, 2018, 57 (19), pp.53305334. 10.1002/anie.201800141 . hal-01969103

\section{HAL Id: hal-01969103 https://hal.sorbonne-universite.fr/hal-01969103}

Submitted on 3 Jan 2019

HAL is a multi-disciplinary open access archive for the deposit and dissemination of scientific research documents, whether they are published or not. The documents may come from teaching and research institutions in France or abroad, or from public or private research centers.
L'archive ouverte pluridisciplinaire HAL, est destinée au dépôt et à la diffusion de documents scientifiques de niveau recherche, publiés ou non, émanant des établissements d'enseignement et de recherche français ou étrangers, des laboratoires publics ou privés. 


\title{
Vesicle Tubulation with Self-Assembling DNA Nanosprings
}

\author{
Michael W. Grome, Zhao Zhang, Frédéric Pincet, and Chenxiang Lin*
}

\begin{abstract}
A major goal of nanotechnology and bioengineering is to build artificial nanomachines capable of generating specific membrane curvatures on demand. Inspired by natural membrane-deforming proteins, we designed DNA-origami curls that polymerize into nanosprings and show their efficacy in vesicle deformation. DNA-coated membrane tubules emerge from spherical vesicles when DNA-origami polymerization or high membrane-surface coverage occurs. Unlike many previous methods, the DNA self-assembly-mediated membrane tubulation eliminates the need for detergents or topdown manipulation. The DNA-origami design and deformation conditions have substantial influence on the tubulation efficiency and tube morphology, underscoring the intricate interplay between lipid bilayers and vesicle-deforming DNA structures.
\end{abstract}

Cons living cells. ${ }^{[1]}$ Tubular shape is one of the most common membrane architectures present during cellular events including endocytosis, viral budding, and cytokinesis. Various membrane-deforming proteins that sense and generate membrane curvatures contribute to the formation and stabilization of membrane tubules in cells. ${ }^{[2]}$ While many existing techniques can recapitulate membrane tubulation in vitro, ${ }^{[3]}$ experimental restraints (for example, dependence on lipid composition, detergents, or mechanical force) pose limitations on a method's programmability and applications.

Stemming from the simple idea of combining a branched DNA motif with complementary "sticky-ends", ${ }^{[4]}$ the field of structural DNA nanotechnology has matured to a stage in which one can easily generate three-dimensional nanostructures with programmable geometry, surface chemistry, and dynamics. ${ }^{[5]}$ In recent years, the field has seen considerable progress towards using DNA nanostructures for membrane engineering to better control synthetic membrane properties as well as to manipulate biological membranes. ${ }^{[6]}$ For example, supported lipid-bilayer membranes have been coated with DNA "rafts" and promoted DNA-tile association, ${ }^{[7]}$ DNA nanochannels labeled with hydrophobic moieties have been developed for membrane penetration, ${ }^{[8]}$ and DNA

[*] M. W. Grome, Dr. Z. Zhang, Dr. F. Pincet, Prof. C. Lin

Department of Cell Biology \& Nanobiology Institute, Yale University 850 West Campus Drive, West Haven, CT 06516 (USA)

E-mail: chenxiang.lin@yale.edu

Dr. F. Pincet

Laboratoire de Physique Statistique, Ecole Normale Supérieure, PSL Research University; Université Paris Diderot Sorbonne Paris Cité; Sorbonne Universités UPMC Univ Paris 06, CNRS 24 rue Lhomond, 75005 Paris (France) Supporting information and the ORCID identification number(s) for the author(s) of this article can be found under: https://doi.org/10.1002/anie.201800141. templates have been engineered to guide the assembly of size- and shape-defined liposomes and to induce membrane fusion and bending. ${ }^{[3 e, 9]}$ Particularly relevant to this work, the lateral association of cholesterol-modified DNA nanoblocks on membrane have led to vesicle flattening, presumably imposed by a large flat DNA surface. ${ }^{[10]}$ Although inserting DNA nanochannels at high concentration can result in tubule-like structures on giant unilamellar vesicles (GUVs), such deformation is likely driven by surface crowding; the exact mechanism remains unclear. ${ }^{[8 \mathrm{~b}]}$ Therefore, engineering DNA nanostructures capable of programmable vesicle tubulation remains challenging.

While existing membrane-deforming DNA structures mostly mimic BAR-family proteins, ${ }^{[10]}$ we took our design inspiration from dynamins ${ }^{[2 \mathrm{a}]}$ and ESCRT machineries, ${ }^{[2 \mathrm{cc}}$ two major classes of proteins that polymerize into helical structures coating lipid tubules. Specifically, we set out to generate DNA curls that would self-assemble into helical structures similar to the Snf7 filament, which form spiral-like assemblies on membrane with an outer diameter of $50-100 \mathrm{~nm}$ and filament thickness of 5-10 nm. ${ }^{[11]}$ To achieve this, we bent and twisted a circa 100-nm long, 14-nm thick DNA 24-helixbundle rod; a $55^{\circ}$ of bend per 77 bp was achieved by inserting and deleting an equal number of base pairs on the opposite sides of the DNA rod ${ }^{[12]}$ and the twist was implemented by changing the bending axis by $30^{\circ}$ every $77 \mathrm{bp}$. The result of such a design is a C-shaped structure with an out-of-plane twist (Figure $1 \mathrm{a}$ and the Supporting Information, Figures S1 and S2). To render the DNA structure with a stronger membrane affinity, we reserved 24 single-stranded DNA (ssDNA) extensions along the inner surface of the DNAorigami curl for attaching amphipathic peptides as membrane anchors, which we designed to mimic the N-terminal ANCHR helix of Snf7. ${ }^{[13]}$ The distance between neighboring peptides is 4-7 nm, close to their circa $3 \mathrm{~nm}$ spacing in snf7 filaments. ${ }^{[14]}$ Gratifyingly, upon conjugation with Cy5-labeled ssDNA, this peptide dissolved readily in detergent-free aqueous buffer solutions, bound well to the attachment sites on the DNA curl, and had minimal tendency to aggregate DNA nanostructures (Figure $1 \mathrm{~b}$ and the Supporting Information, Figure S3). We further designed a set of linker strands that would bridge the front and rear ends of the DNA curls, causing monomeric DNA curls to polymerize and form "nanosprings" with an expected inner diameter of $27 \mathrm{~nm}$ and a helical pitch of $53 \mathrm{~nm}$. Indeed, adding linkers to the peptide-labeled DNA curls triggered polymerization; when examined by negativestain transmission electron microscopy (TEM), the resulting nanosprings had a length of $330 \pm 190 \mathrm{~nm}$ with an inner diameter of $26 \pm 5 \mathrm{~nm}$ and a helical rise of $80 \pm 9 \mathrm{~nm}$ (Figure $1 \mathrm{c})$. The discrepancy between designed and measured nanospring dimensions is likely due to the structural distortion on the TEM grids ${ }^{[15]}$ and the overwound DNA caused 

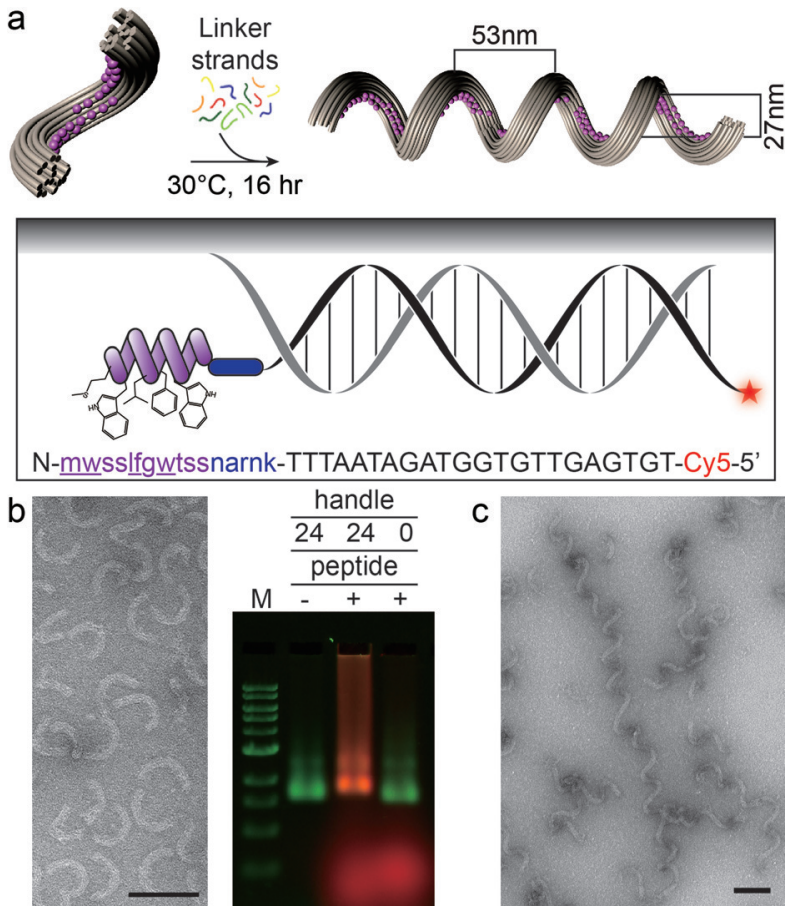

Figure 1. a) Top: The design of a 24-helix-bundle DNA curl (bent grey cylinders) labeled with up to 24 amphipathic membrane-binding molecules (purple spheres) and the linker-strand triggered polymerization of such curls into a left-handed DNA nanospring. Bottom: Model and sequence of the DNA-peptide conjugate that decorates the interior of the DNA curl (hydrophobic amino acids are underlined). b) Assembly results of the peptide-labeled DNA-curl monomers. Left: A negative-stain TEM image of the purified monomeric curls. Right: An agarose gel resolving DNA curls with and without ssDNA extensions (handles) in the presence and absence of Cy5-modified DNApeptide conjugates. Pseudo-color fluorescence: red $=\mathrm{Cy} 5$, green $=$ ethidium bromide. c) A TEM image of DNA nanosprings. Scale bars $=100 \mathrm{~nm}$.

by numerically balanced insertions and deletions. ${ }^{[16]}$ A considerable amount of closed DNA circles also emerged after addition of linkers as a result of self-closing dimers. It is worth noting that the DNA-curl polymerization is tunable by changing $\mathrm{Mg}^{2+}$ and $\mathrm{K}^{+}$concentrations. The polymerization in solution is optimal at $10 \mathrm{~mm} \mathrm{Mg}^{2+}$ without $\mathrm{K}^{+}$; higher $\mathrm{Mg}^{2+}$ promoted nanospring aggregation and higher $\mathrm{K}^{+}$led to shorter polymers (Supporting Information, Figure S4).

After establishing the folding of DNA curls and their polymerization in solution, we tested their ability to bind and deform vesicles. The experimental procedure is summarized in Figure 2a. Briefly, purified DNA-curl monomers (4 nм) labeled by ANCHR-mimicking peptide were incubated with extruded liposomes (99.2 $\mu$ M 1,2-dioleoyl-sn-glycero-3-phosphocholine or DOPC, $0.8 \mu \mathrm{M}$ 1,2-dioleoyl-sn-glycero-3-phosphoethanolamine-N-(lissamine rhodamine B sulfonyl); mean diameter $=134 \mathrm{~nm}$ ) at $4{ }^{\circ} \mathrm{C}$ for $1 \mathrm{~h}$ to allow for binding before mixed with linker strands and further incubated at $30^{\circ} \mathrm{C}$ for up to $32 \mathrm{~h}$; the osmolarity of the solution was kept constant throughout the entire process. TEM analyses (Figure $2 \mathrm{~b}$ ) on the mixture of DNA curls and liposomes showed their binding depended on the presence of membrane anchors. To better analyze the liposome binding affinity, we subjected the
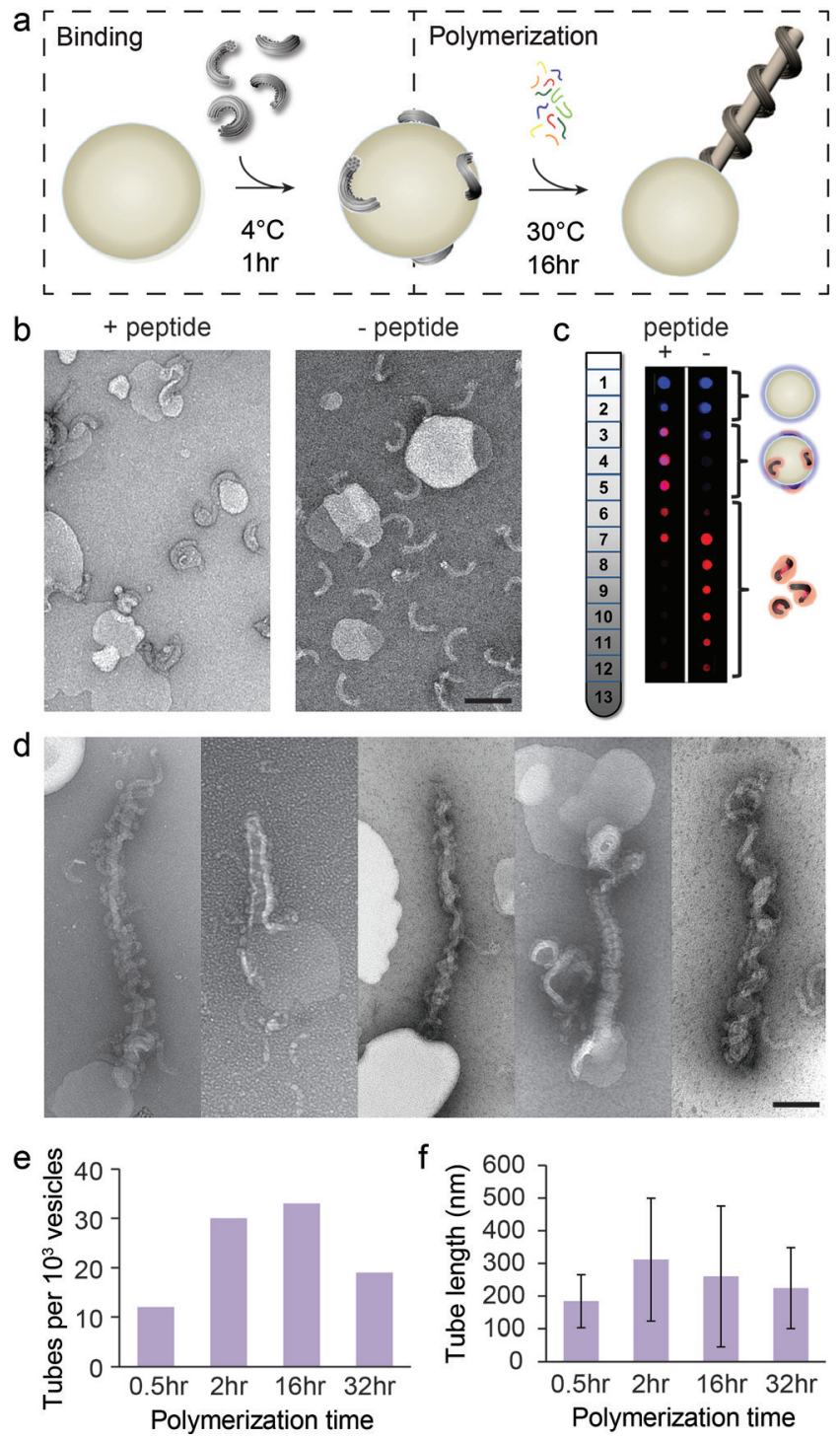

Figure 2. a) A schematic of the two-step deformation experiment. b) TEM images of rhodamine-labeled DOPC LUVs after incubation with DNA curls carrying Cy5-labeled DNA-peptide conjugate (left) and Cy5-labeled ssDNA only (right). c) The mixtures shown in (b) after isopycnic centrifugation. Pseudo-color fluorescence of recovered fractions: red $=C y 5$, blue $=$ rhodamine. Smaller numbers denote lighter fractions. d) TEM images of deformed vesicles after the polymerization step. e) Deformation efficiency and f) membrane tubule length as a function of polymerization time. Error bars $=S D$. For each deformation experiment, 1400-2000 vesicles were examined (e) and 17-23 tubules were measured (f). [DNA curl] $=4 \mathrm{~nm}$, [lipid] $=100 \mu \mathrm{m}$. Scale bars $=100 \mathrm{~nm}$.

mixture of DNA-curl monomers and liposomes to isopycnic centrifugation. A fluorescence scan of the recovered fractions confirmed the membrane-anchor-dependent binding between Cy5-labeled DNA curls and rhodamine-labeled vesicles (Figure $2 \mathrm{c}$ ), which co-migrated with amphipathic peptides decorating DNA curls but parted ways in the absence of these peptides. However, in addition to DNA-curl-bound liposomes, TEM revealed free DNA curls and naked liposomes in the fractions in which the two coexisted (Supporting Information, Figure S5), suggesting their binding is transient. 
Interestingly, individual ANCHR-mimicking-peptide-DNA conjugate molecules showed no detectable affinity towards vesicles (Figure S5), highlighting the DNA curl's role in facilitating membrane binding, possibly by both bringing together multiple (a maximum of 24) membrane anchors and providing a negatively charged surface to interact with the zwitterionic lipid head group in the presence of magnesium cations. Adding linker strands after the initial binding step resulted in the formation of membrane tubules wrapped by DNA nanosprings (Figure 2d and the Supporting Information, Figure S6). Among the deformed liposomes, some retained a spherical body with a tubule protruding outwards while others turned entirely into a tubular shape. A timecourse study showed that the tubule abundance and length reached maximum after the first two hours of polymerization and stayed stable for $16 \mathrm{~h}$; another 16 -h incubation at $30^{\circ} \mathrm{C}$ led to fewer and shorter tubules, likely because of degradation (Figures 2e and S6). We note that vesicle tubulation occurred in a solution with $10 \mathrm{~mm} \mathrm{Mg}^{2+}$ and $100-800 \mathrm{~mm} \mathrm{~K}^{+}$, despite the fact that the DNA-curl polymerization in solution was most efficient without $\mathrm{K}^{+}$. This is because monovalent cations weaken the electrostatic interactions between DNA and lipid, hence mitigating DNA-curl-induced vesicle aggregation (Supporting Information, Figures S7 and S8). Neither polymerizing membrane-anchor-free DNA curls in the presence of vesicles (Supporting Information, Figure S9) nor incubating pre-polymerized membrane-anchor-labeled DNA nanosprings with vesicles (Supporting Information, Figure S10) could generate membrane tubules, indicating that vesicle tubulation requires membrane-binding DNA-curl monomers. Despite the low deformation yield $(<4 \%$ of vesicles were deformed after $16 \mathrm{~h}$ ), the membrane tubules unambiguously formed as a result of DNA-nanostructure coating. In fact, nuclease digestion of the DNA coat after tubulation resulted in the disappearance of the vast majority of membrane protrusions and tubular vesicles (Supporting Information, Figure S11).

A closer inspection of the apparent membrane tubule width and the associated nanospring periodicity identified two types of tubes (Figure $3 \mathrm{a}$ ). The first type features a tubule diameter of $15 \pm 2 \mathrm{~nm}$ and an apparent helical pitch of $35 \pm$ $6 \mathrm{~nm}$ (peak-to-peak distance of the DNA coat). The second type of tubule is considerably wider (diameter $=29 \pm 4 \mathrm{~nm}$ ) with a more densely packed DNA-curl coating (apparent pitch $=16 \pm 2 \mathrm{~nm}$ ). In rare cases, a continuous membrane tubule exhibits both morphologies in different segments. One possible explanation is that the wider tubes resulted from the dehydration and flattening of the thinner tubes on the TEM grids. An alternative hypothesis is that both types of membrane tubules existed in solution and the wider ones formed because of higher membrane coverage by the DNA curls. To test this hypothesis, we increased the concentration of DNA-curl monomers from $4 \mathrm{~nm}$ to a maximum of $20 \mathrm{~nm}$, which translates to an increase of the maximal vesicle-surface coverage from $16 \%$ to $80 \%$. The higher surface coverage led to two significant changes (Figure $3 \mathrm{~b}, \mathrm{c}$ and the Supporting Information, Figure S12). First, the overall deformation yield (the portion of vesicles that undergo notable tubulation) increased with a higher initial concentration of DNA-curl
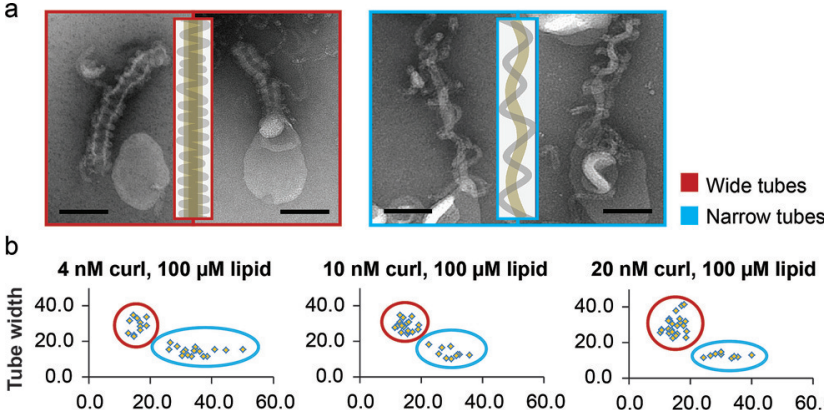

$10 \mathrm{nM}$ curl, $100 \mu \mathrm{M}$ lipid
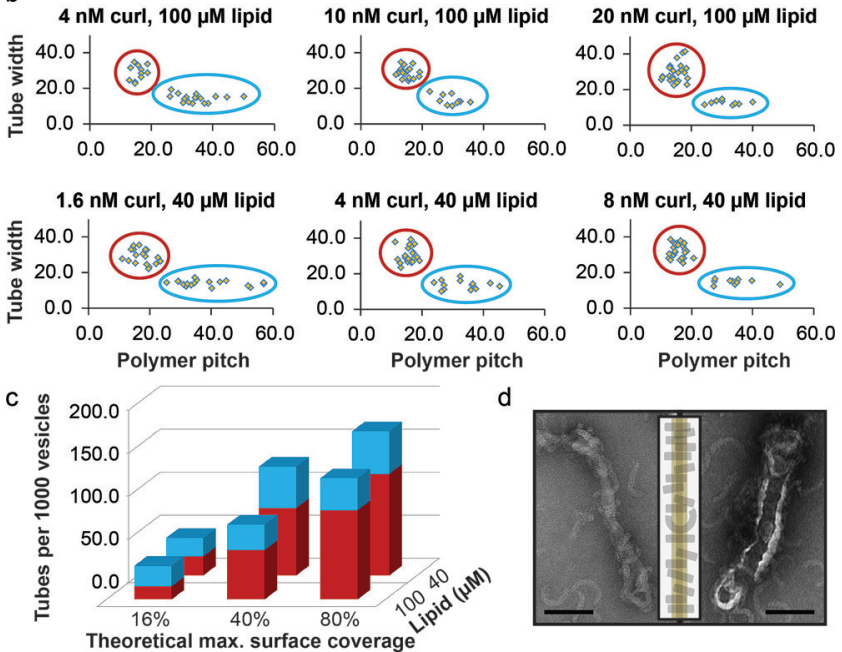

Figure 3. a) Two types of membrane tubule morphologies under negative-stain TEM. A model (yellow= membrane tubule, grey=DNA nanosprings) is placed over representative images. b) Membrane tubule morphologies (characterized by width vs. apparent nanospring pitch) resulting from six different lipid and DNA-curl concentrations. Red and blue circles highlight the wide and narrow tube populations, respectively. For each scatter plot, 20-27 tubules were analyzed by TEM. c) Tubule abundance and morphology as a function of vesiclesurface coverage by DNA curls at two lipid concentrations. For each bar, 800-4200 vesicles were examined by TEM. The ratio between wide (red) and narrow (blue) tubes was extracted from (b). d) Linkerindependent tubulation. A model is placed over negative-stain TEM images. DOPC vesicles were incubated with amphipathic-peptidelabeled DNA curls first at $4{ }^{\circ} \mathrm{C}$ for $1 \mathrm{~h}$ and then at $30^{\circ} \mathrm{C}$ for $16 \mathrm{~h}$; linker strands, if used, were added after the first hour. Scale bars $=100 \mathrm{~nm}$.

monomers, up to circa $13 \%$ with 20 nm DNA curls. Second, the occurrence of wider tubules increased with greater membrane coverage and dominated the tubule population with DNA-curl concentration greater than $10 \mathrm{~nm}$ (or roughly $40 \%$ maximal surface coverage). Reducing the DNA curl and lipid concentration proportionally resulted in a similar trend, confirming that surface coverage is the main determinant of deformation efficiency and tubule morphology (Figure $3 \mathrm{c}$ and the Supporting Information, Figure S13). Based on these data, our interpretation is that the wider tubules' diameters are likely defined by the multiple, moderately compressed DNA springs, whereas the narrower tubes, surrounded by only 1-2 slightly compressed springs are free to adjust their diameters to approach the minimum allowed by the membrane bending energy (see Technical Notes in the Supporting Information). The compressed DNA springs have to adhere to the membrane with sufficient strength (through both electrostatic and hydrophobic interactions) to prevent the retraction of lipid tubules, which exposes the membrane anchors. Intriguingly, an appreciable amount of tubules (width $=24 \pm 8 \mathrm{~nm}$, max. yield $\approx 5 \%$ ) was produced under 
high membrane coverage conditions (Figure 3d and the Supporting Information, Figure S14) without linker strands, in which the tubules were covered by DNA curls, but with less regular patterns. This linker-independent tubulation suggests a different, although less efficient, deformation mechanism driven by surface crowding and membrane-anchor insertion, consistent with the notion of coupling between protein/lipid shape and membrane curvature. ${ }^{[1,17]}$

Having confirmed the DNA nanospring's capability in deforming organelle-sized large unilamellar vesicles (LUVs), we attempted to test their tubulation efficacy on GUVs with sizes approximating eukaryotic cells. We first incubated Cy5labeled DNA-origami curls with nitrobenzoxadiazole (NBD)labeled GUVs (lipid concentration $\approx 10 \mu \mathrm{M}$ ) at $4{ }^{\circ} \mathrm{C}$ for $1 \mathrm{~h}$ in an iso-osmotic buffer solution containing $10 \mathrm{mM} \mathrm{Mg}^{2+}$ and $100 \mathrm{~mm} \mathrm{~K}^{+}$. We then held this mixture (with or without additional linker strands) at $30^{\circ} \mathrm{C}$ for $16 \mathrm{~h}$ and monitored vesicles by using a confocal fluorescence microscope. The DNA curls bound to GUVs (Figure 4a) in a similar way as

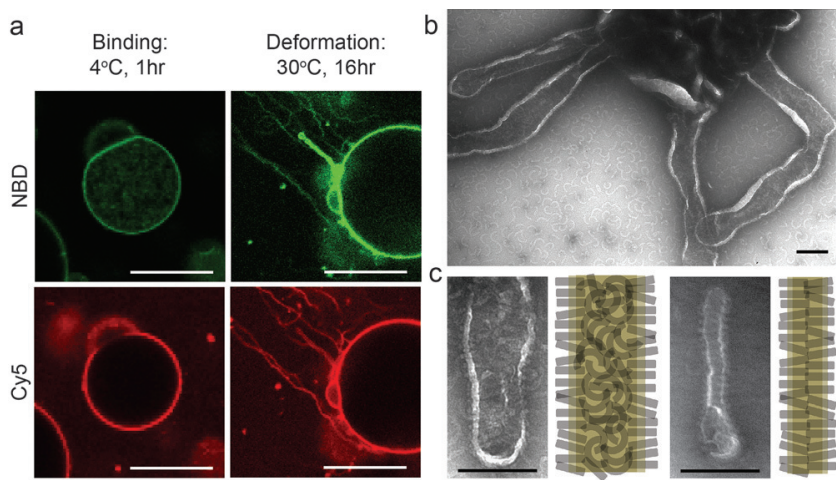

Figure 4. a) Fluorescence microscopy images showing the NBD-labeled DOPC GUVs binding with (left) and deformed by (right) Cy5labeled DNA curls carrying amphipathic peptides in the absence of linker strands. Red $=c y 5$, green $=$ NBD. Scale bars $=25 \mu \mathrm{m}$. b) A negative-stain TEM image showing a deformed GUV. Scale bar $=200 \mathrm{~nm}$. c) Close-ups of deformed vesicles under negative-stain TEM. A model (yellow $=$ membrane tubule, grey=DNA curls) is placed to the right of the corresponding image. The tube in the left image is attached to a GUV (not shown). Scale bars $=200 \mathrm{~nm}$.

they bound to LUVs. The surface coverage of DNA curls depended on their initial concentration and membraneanchor density (Supporting Information, Figure S15); the bound and unbound DNA curls were in a dynamic equilibrium with a slow off-rate (Supporting Information, Figure S16). With $20 \mathrm{~nm}$ DNA curls, noticeable tubulation occurred after at least $1.5 \mathrm{~h}$ of incubation at $30^{\circ} \mathrm{C}$. After $16 \mathrm{~h}$, these outward protrusions grew long (some longer than $250 \mu \mathrm{m})$ and abundant. The tube-like structures showed both Cy5 and NBD fluorescence (Figure 4a), suggesting they were coated by DNA curls, as confirmed by negative-stain TEM studies. Under TEM, a deformed GUV usually featured multiple emanating protrusions (Figure 4b). Compared to the membrane tubules originated from LUVs, these GUV protrusions were much wider $(116 \pm 50 \mathrm{~nm})$ with an extremely dense DNA coating. The DNA curls lay closely against one another in parallel at the edges of the protrusions but showed no apparent order in the central areas, albeit at a high surface density (Figure $4 \mathrm{c}$ ). We found that the linker strands, but not the membrane-binding DNA curls, were dispensable for tubulation (Supporting Information, Figure S17); the vesicles were deformed rather similarly with or without linkers (Supporting Information, Figures S18 and S19). Furthermore, DNA curls with cholesterol modification and DNA rings (outer diameter $=60 \mathrm{~nm}$ ) with ANCHRmimicking peptide modification on the inside deformed vesicles (GUVs and LUVs) in a similar manner and without linker-induced DNA-origami oligomerization (Supporting Information, Figure S20-S23). Changing peptide anchors to cholesterol increased the aggregation of DNA curls but did not reduce their tubulation capability in general. Although the influence of membrane-anchor type and DNA nanostructure geometry on vesicle deformation warrants further study, the phenomena observed in this study, combined with the linker-independent LUV deformation, strongly support that DNA-origami structures can drive vesicle tubulation solely by introducing a large number of membrane anchors and covering the vesicle surface with DNA structures at high density.

In summary, we have built bioinspired nanostructures that drive tubular deformations from spherical vesicles. Such a membrane-sculpting structure comprises three modules, a structural module (the curved DNA-origami body) that provides a negatively charged interior with dozens of "open seats" (ssDNA extensions) for guest molecules, a membraneanchoring module (DNA-peptide or DNA-cholesterol conjugate) that decorates the DNA curl's inner surface and confers hydrophobicity, and a connector module (linker strands) that join the ends of monomeric structures to form a long helical filament. Both membrane incorporation and DNA-origami polymerization provide energy to overcome membrane tension and intrinsic curvature for vesicle deformation. Embedding amphipathic anchors into lipid bilayers expands the outer leaflet and introduces higher membrane curvature; the elongation of DNA springs "pulls" on the lipid and "holds" the shape of the membrane tubules (see Technical Notes in the Supporting Information). The vesicle deformation takes two different forms that both require the membrane-anchoring module and DNA structures surrounding the membrane tubules but result in distinct tubule morphology and DNA-coating patterns. This process can be modulated by changing the surface density of DNA nanostructures (systematically tested) and the membrane tension of the vesicles (uncontrolled in this study). With sparse DNA coating and high membrane tension, the connector module is essential for making tubules wrapped by nanosprings. In contrast, when a low-tension membrane surface is saturated with membrane-anchor-labeled DNA structures, low-energycost polymerization-independent tubulation becomes favorable. This may explain the dispensable linker strands in GUV deformation, in which membrane tension is likely lowered due to evaporation and the DNA curls are in circa 8-fold excess for complete membrane coverage. Additionally, both higher surface coverage and lower membrane tension can increase tubulation efficiency. Tension-dependent vesicle tubulation has been demonstrated using motor proteins, ${ }^{[3 c]}$ 
and concentration-dependent self-assembly on membrane has been observed with curvature sensing/inducing proteins (for example, amphiphysin ${ }^{[17 b]}$ and Fts $^{[18]}$ ). Deforming membranes with engineered synthetic constructs in a way that resembles the work of naturally existing proteins not only is a major feat in synthetic biology ${ }^{[19]}$ but also provides a tool to study the membrane remodeling mechanisms. The modular self-assembling nanosprings extend our membrane-manipulating capability and pave the way for future development of more sophisticated, multistep membrane-sculpting machineries (for example, with pre-inhibited components that are activated upon membrane binding) that can sort cargo molecules, drive vesicle budding, alter deformation topology (that is, tubulation toward vesicle lumen), and act on cell membranes.

\section{Acknowledgements}

We thank C. G. Burd for discussion and designing ANCHRmimicking peptide. This work is supported by a National Institutes of Health (NIH) Director's New Innovator Award (DP2-GM114830), an NIH grant (R21-GM109466), and a Yale University faculty startup fund to C.L. and a European Research Council (ERC) funded grant under the European Union's Horizon 2020 research and innovation programme (grant agreement no. 669612) to F.P. In addition, M.W.G. is supported by an NIH training grant (T32-GM007499).

\section{Conflict of interest}

The authors declare no conflict of interest.

Keywords: DNA nanotechnology - DNA origami . membrane deformation $\cdot$ self-assembly $\cdot$ vesicles

[1] H. T. McMahon, J. L. Gallop, Nature 2005, 438, 590-596.

[2] a) S. M. Ferguson, P. De Camilli, Nat. Rev. Mol. Cell Biol. 2012, 13, 75-88; b) A. Frost, V. M. Unger, P. De Camilli, Cell 2009, 137, $191-196$; c) J. H. Hurley, P. I. Hanson, Nat. Rev. Mol. Cell Biol. 2010, 11, 556-566.

[3] a) P. Xu, G. Tan, J. Zhou, J. He, L. B. Lawson, G. L. McPherson, V. T. John, Langmuir 2009, 25, 10422-10425; b) A. Zidovska, K. K. Ewert, J. Quispe, B. Carragher, C. S. Potter, C. R. Safinya, Methods Enzymol. 2009, 465, 111 -128; c) A. Roux, G. Cappello, J. Cartaud, J. Prost, B. Goud, P. Bassereau, Proc. Natl. Acad. Sci.
USA 2002, 99, 5394-5399; d) A. Diz-Muñoz, D. A. Fletcher, O. D. Weiner, Trends Cell Biol. 2013, 23, 47-53; e) Z. Zhang, Y. Yang, F. Pincet, M. C. Llaguno, C. Lin, Nat. Chem. 2017, 9, 653659.

[4] N. C. Seeman, J. Theor. Biol. 1982, 99, 237-247.

[5] a) F. Hong, F. Zhang, Y. Liu, H. Yan, Chem. Rev. 2017, 117, $12584-12640 ;$ b) N. C. Seeman, H. F. Sleiman, Nat. Rev. Mater. 2017, 3, 17068.

[6] a) S. Howorka, Nat. Nanotechnol. 2017, 12, 619-630; b) M. Langecker, V. Arnaut, J. List, F. C. Simmel, Acc. Chem. Res. 2014, 47, $1807-1815$.

[7] a) N. Avakyan, J. W. Conway, H. F. Sleiman, J. Am. Chem. Soc. 2017, 139, 12027-12034; b) A. Johnson-Buck, S. Jiang, H. Yan, N. G. Walter, ACS Nano 2014, 8, 5641-5649; c) Y. Suzuki, M. Endo, H. Sugiyama, Nat. Commun. 2015, 6, 8052.

[8] a) J. R. Burns, A. Seifert, N. Fertig, S. Howorka, Nat. Nanotechnol. 2016, 11, 152-156; b) K. Göpfrich, T. Zettl, A. E. Meijering, S. Hernandez-Ainsa, S. Kocabey, T. Liedl, U. F. Keyser, Nano Lett. 2015, 15, 3134-3138; c) M. Langecker, V. Arnaut, T. G. Martin, J. List, S. Renner, M. Mayer, H. Dietz, F. C. Simmel, Science 2012, 338, $932-936$.

[9] a) S. D. Perrault, W. M. Shih, ACS Nano 2014, 8, 5132-5140; b) Y. Yang, J. Wang, H. Shigematsu, W. Xu, W. M. Shih, J. E. Rothman, C. Lin, Nat. Chem. 2016, 8, 476-483.

[10] a) A. Czogalla, D. J. Kauert, H. G. Franquelim, V. Uzunova, Y. Zhang, R. Seidel, P. Schwille, Angew. Chem. Int. Ed. 2015, 54, 6501-6505; Angew. Chem. 2015, 127, 6601-6605; b) S. Kocabey, S. Kempter, J. List, Y. Xing, W. Bae, D. Schiffels, W. M. Shih, F. C. Simmel, T. Liedl, ACS Nano 2015, 9, 3530-3539.

[11] a) P. I. Hanson, R. Roth, Y. Lin, J. E. Heuser, J. Cell Biol. 2008, 180, 389-402; b) W. M. Henne, N. J. Buchkovich, Y. Zhao, S. D. Emr, Cell 2012, 151, 356-371; c) N. Chiaruttini, L. RedondoMorata, A. Colom, F. Humbert, M. Lenz, S. Scheuring, A. Roux, Cell 2015, 163, 866-879.

[12] H. Dietz, S. M. Douglas, W. M. Shih, Science 2009, 325, 725-730.

[13] N. J. Buchkovich, W. M. Henne, S. Tang, S. D. Emr, Dev. Cell 2013, 27, $201-214$.

[14] S. Tang, W. M. Henne, P. P. Borbat, N. J. Buchkovich, J. H. Freed, Y. Mao, J. C. Fromme, S. D. Emr, eLife 2015, 4, e12548.

[15] A. M. Maier, W. Bae, D. Schiffels, J. F. Emmerig, M. Schiff, T. Liedl, ACS Nano 2017, 11, 1301-1306.

[16] D. N. Kim, F. Kilchherr, H. Dietz, M. Bathe, Nucleic Acids Res. 2012, 40, 2862-2868.

[17] a) I. R. Cooke, M. Deserno, Biophys. J. 2006, 91, 487-495; b) B. Sorre, A. Callan-Jones, J. Manzi, B. Goud, J. Prost, P. Bassereau, A. Roux, Proc. Natl. Acad. Sci. USA 2012, 109, 173-178.

[18] J. Mingorance, M. Tadros, M. Vicente, J. M. Gonzalez, G. Rivas, M. Velez, J. Biol. Chem. 2005, 280, 20909-20914.

[19] A. Czogalla, H. G. Franquelim, P. Schwille, Biophys. J. 2016, 110, 1698- 1707 . 